\title{
PELATIHAN PEMBUATAN LOGO DENGAN APLIKASI PIXELAB PESANTREN MAHASISWA UNILAK (PMU)
}

\author{
Ahmad Zamsuri ${ }^{1}$, Susi Handayani ${ }^{2}$, Arpan ${ }^{3}$ \\ 1,2,3 Universitas Lancang Kuning, Pekanbaru, Indonesia \\ Jalan Yos Sudarso KM. 08 Rumbai, Pekanbaru-Riau, (0761) 53108 -53236 \\ email ${ }^{1}$ ahmadzamsuri@unilak.ac.id, ${ }^{2}$ susihandayani@unilak.ac.id, ${ }^{3}{ }^{2}$ arpanhafiz1106@gmail.com
}

\begin{abstract}
Abstrak: Aplikasi Pixellab merupakan aplikasi yang dapat digunakan dalam pembuatan logo yang berbasis android. Dengan pemanfaatan dan pengembangkan teknik dalam pembuatan logo Dalam hal ini, pemanfaatan media yang menarik dan tepat guna dalam proses pembuatan logo pelatihan akan memiliki dampak positif yang akan sangat berpotensi meningkatkan kemampuan mahasantri dalam membuat logo dengan aplikasi pixellab. Para mahasantri sangat membutuhkan pengetahuan dalam membuat logo dengan tujuan memberikan bekal dalam pembuatan logo walaupun mahasantri terdiri dari banyak prodi yang ada di Unilak. Oleh sebab itu, tim pengusul program Pengabdian Kepada Masyarakat menawarkan solusi berupa Pelatihan Pembuatan Logo Dengan Aplikasi Pixellab Untuk Pesantren Mahasiswa Universitas Lancang Kuning Pekanbaru. Di mana program ini diharapkan mampu menjadi wadah dan inspirasi bagi para mahasantri dapat menambah pengetahuan dalam membuat logo dengan aplikasi pixellab besar harapan mahasantri dapat mengikuti proses pelatihan pembuatan logo dengan aplikasi pixellab dan mahasantri lebih mampu menghasilkan karya yang dapat merangsang daya tarik dalam pembuatan logo dengan menarik dan unik. Sebagai pemateri memberikan sosialisasi dan sekaligus pendampingan mengenai bagaimana pembuatan logo dengan aplikasi pixellab yang menarik dan pastinya sagat dapat bermanfaat.
\end{abstract}

Kata Kunci: Logo, Aplikasi Pixellab, Pesantren Mahasiswa Unilak

\begin{abstract}
The Pixellab application is an application that can be used in making Android-based logos. By using and developing techniques in making logos. In this case, the use of attractive and appropriate media in the process of creating a training logo will have a positive impact which will greatly improve the ability of students to create logos with the Pixellab application. The students really need knowledge in making logos with the aim of providing provisions in making logos even though the students consist of many study programs at Unilak. Therefore, the team that proposed the Community Service program offered a solution in the form of Training on Logo Making with the Pixellab Application for Islamic Boarding School Students at the Lancang Kuning University Pekanbaru. Where this program is expected to be a forum and inspiration for students to increase knowledge in making logos with the Pixellab application, we hope that students can take part in the training process of making logos with the Pixellab application and students will be more able to produce works that can encourage attractiveness in making logos attractively. and unique. As a presenter, he provides socialization and at the same time assistance on how to make a logo with the Pixellab application which is interesting and certainly useful.
\end{abstract}

Keywords: Logo, Pixellab Application, Unilak Student Islamic Boarding School 


\section{Pendahuluan}

Pesantren Mahasiswa Universitas Lancang Kuning (PMU) merupakan program kerjasama Universitas Lancang Kuning (UNILAK) dengan Badan Amil Zakat Nasional (BAZNAS) Provinsi Riau. PMU resmi berdiri tahun 2020 dengan jumlah mahasiswa santri sebanyak 25 mahasiswa UNILAK yang aktif dan sebagai mahasiswa baru 2020/2021. PMU ini berada di RUSUNAWA UNILAK segala aktivitas santri mahasiswa dari pemondokan dan proses belajar mengajar dilakasakan di gedung RUSUNAWA UNILAK. PMU memiliki beberapa program unggulan diataranya program kewirausahaan dimana disamping mahasiswa menimba ilmu agama, mahasiswa juga dibekali pengetahuan kewirausahaan sehingga diharapkan tatkala mahasiwa tamat dari kuliah dan pesantren, mahasantri dapat memperaktekkan pengetahuan setelah terjun ditengah-tengah masyarakat dengan berinovasi dalam bidang kewirausahaan seusai keinginan dan keilmuan yang dimiliki oleh mahasantri. Kegiatan pengabdian masyarakat ini memiliki target yaitu mahasantri dapat menggunakan keahlian yang diperoleh selama proses pelatihan dapat berguna kedepannya untuk memberikan pengetahuan dalam pembuatan logo dengan menggunakan aplikasi pixellab.

\section{Metode}

Kegiatan pengabdian masyarakat ini memiliki target yaitu Mahasantri PMU dapat menggunakan keahlian yang diperoleh selama proses pelatihan pembuatan logo dengan aplikasi pixellab dapat berguna kedepannya untuk menumbuhkan jiwa kewirausahaan Mahasantri PMU.

Peserta berasal dari Mahasantri, sebanyak 25 orang yang terdiri dari Mahasantri. Peserta diharapkan dapat mempelajari serta menerapkan pengetahuan membuat logo dengan aplikasi pixellab yang menarik secara maksimnal. Luaran kegiatan ini minimal mampu:

a. Mampu memahami dasar dari proses pembuatan logo dengan aplikai pixellab awal dalam menjadi kewirausahaan yang handal.

b. Mampu mengembangkan hasil pembelajaran sesuai dengan kebutuhan Mahasantri.

Penilaian kegiatan ini sebagai berikut:

a. Tingkat kehadiran peserta minimal 95\%.

b. Kegiatan pelatihan telah dilaksanakan.

c. Minimal $80 \%$ mampu menguasai bagaimana menjadi seorang wirausaha.

d. Terciptanya inovasi Mahasantri dalam berwirausaha sesuai kebutuhan Mahasantri.

\section{Hasil dan Pembahasan}

Pada saat pelaksanaan kegiatan ini penulis dan tim banyak sekali mendapatkan aprisiasi, terutama oleh para peserta mahasantri dan sekaligus oleh Direktur PMU yang merasa dapat menambah pengetahuan mahasantri cara membuat logo dengan menggunakan aplikasi pixellab. 


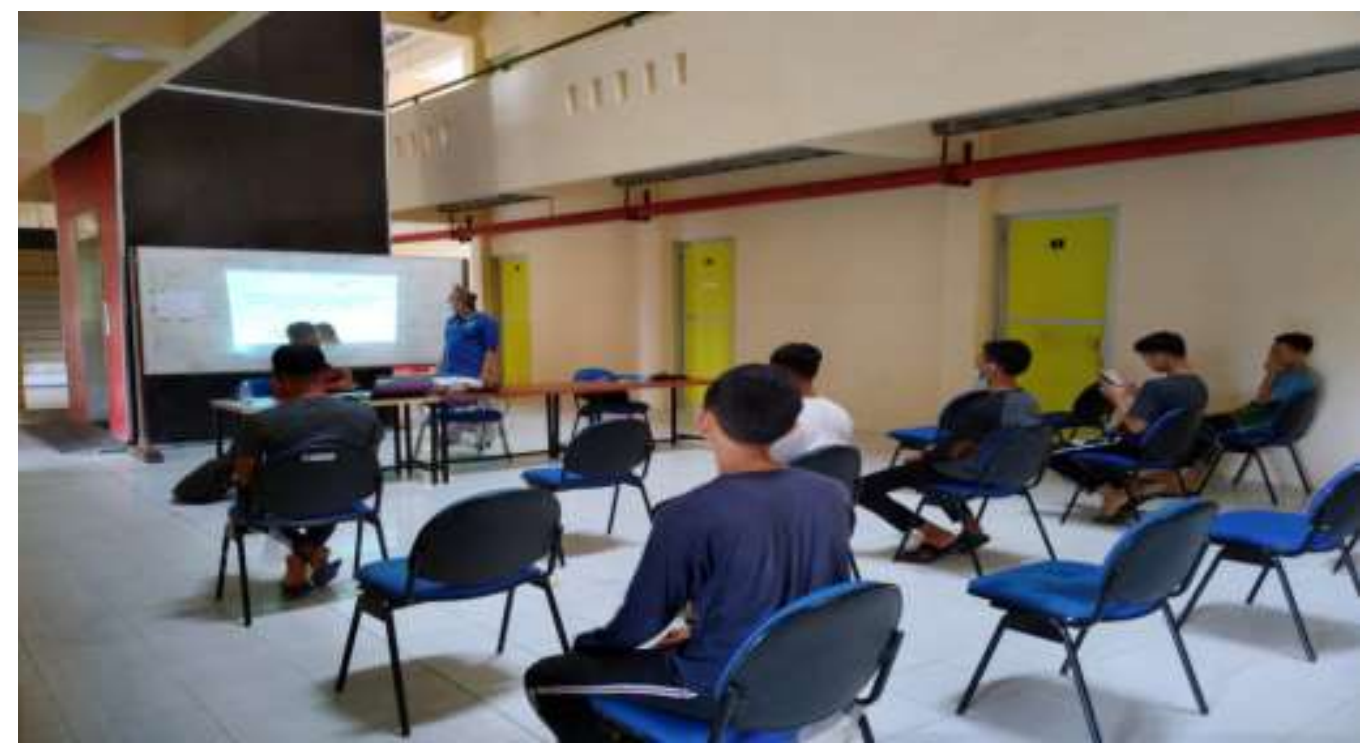

Gambar 1. Pelaksanaan Pelatihan Pembuatan Logo Dengan Aplikasi Pixellab Pengabdian Masyarakat

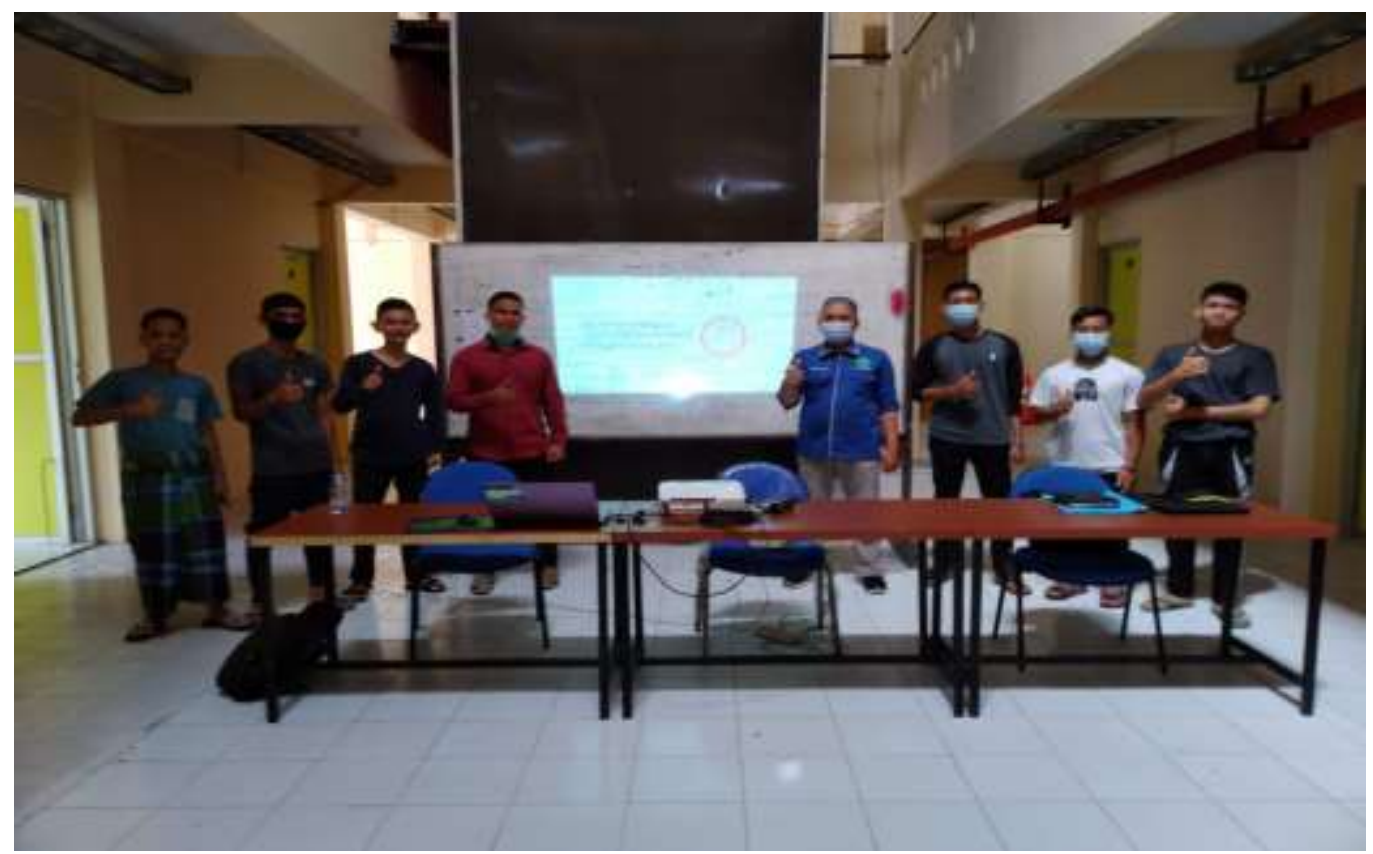

Gambar 2. Setelah Kegiatan Pelatihan Pengabdian Masyarakat

Adapun pelaksanaan kegiatan ini di lakukan dengan praktek langsung di PMU dengan mengikuti protocol kesehatan covid -19 , dengan harapan segala informasi yang telah diberikan dapat di manfaatkan dengan semaksimal mungkin. Adapun Tahapan tahapan yang pemateri sampaikan antara lain yaitu:

1. Melakukan pembekalan pemahaman bagi peserta mengenai bagaimana cara membuat logo dengan aplikasi pixellab berbasis android yang baik. (Sosialisasi) Mengenalkan apa itu aplikasi pixellab secara lengkap.

2. Melakukan install pada aplikasi pixellab dan test pengetahuan dasar dari peserta pelatihan. 
3. Pelatihan langsung di smartphone masing-masing peserta dengan aplikasi pixellab.

4. Peserta pelatihan di uji dengan membuat logo dengan menggunakan aplikasi pixellab yang menarik dengan tema dan konsep yang mereka sukai.

5. Penyebaran kuisioner kepada seluruh peserta pelatihan terhadap apa yang sudah di dapat.

6. Diskusi dan foto bersama.

Tingkat keberhasilan dari pelatihan pembuatan biografi berbasis multimedia diukur menggunakan kuisioner yang diberikan kepada peserta pelatihan. Hasil perhitungan kuisioner ini nantinya akan dapat menentukan seberapa jauh pemahaman peserta terhadap materi dan pelatihan yang di dapat dalam proses yang sudah penulis rincikan dan terangkan tersebut.

Pada kuisioner yang disebar ini diberikan pertanyaan sebanyak 10 total pertanyaan yang terdiri dari 2 tahapan daftar pertanyaan, yaitu 5pertanyaan di. Pertanyaan Umum ,dan 5 lagi pertanyaan Pertanyaan Khusus

Skor untuk setiap jawaban adalah :

1. = Sangat Tidak Setuju (STS)

2. = Tidak Setuju (TS)

3. = Setuju (S)

4. = Sangat Setuju (SS)

Jumlah responden 11 orang sehingga didapat hasil skor dari untuk pertanyaan yang diajukan kepada responden adalah sebagai berikut :

Tabel 1. Hasil Skor Penyebaran Kuisioner

\begin{tabular}{|c|l|c|c|c|c|c|}
\hline \multirow{2}{*}{ NO } & \multirow{2}{*}{ NAMA } & \multicolumn{5}{c|}{ PERTANYAN } \\
\cline { 3 - 7 } & & P1 & P2 & P3 & P4 & P5 \\
\hline 1 & ANANDA & 4 & 4 & 4 & 3 & 4 \\
\hline 2 & ALDISON & 4 & 3 & 4 & 4 & 4 \\
\hline 3 & ILHAM & 4 & 4 & 4 & 3 & 4 \\
\hline 4 & HERMAN & 4 & 4 & 4 & 4 & 4 \\
\hline 5 & LIAN & 4 & 3 & 4 & 4 & 4 \\
\hline 6 & RIZKI & 4 & 4 & 4 & 4 & 4 \\
\hline 7 & RAHMAT & 4 & 4 & 4 & 4 & 4 \\
\hline 8 & IBNU & 4 & 4 & 4 & 4 & 4 \\
\hline 9 & HABDULZIKRI & 4 & 4 & 4 & 3 & 4 \\
\hline 10 & TENGKU & 4 & 4 & 4 & 3 & 4 \\
\hline
\end{tabular}

Maka dari data diatas dapat ditarik kesimpulan yaitu bahwa semua peserta pelatihan memahami cara membuat logo dengan menggunakan aplikasi Pixellab menginginkan penerapannya segera di realisasi, seperti hasil dari table dibawah ini. 


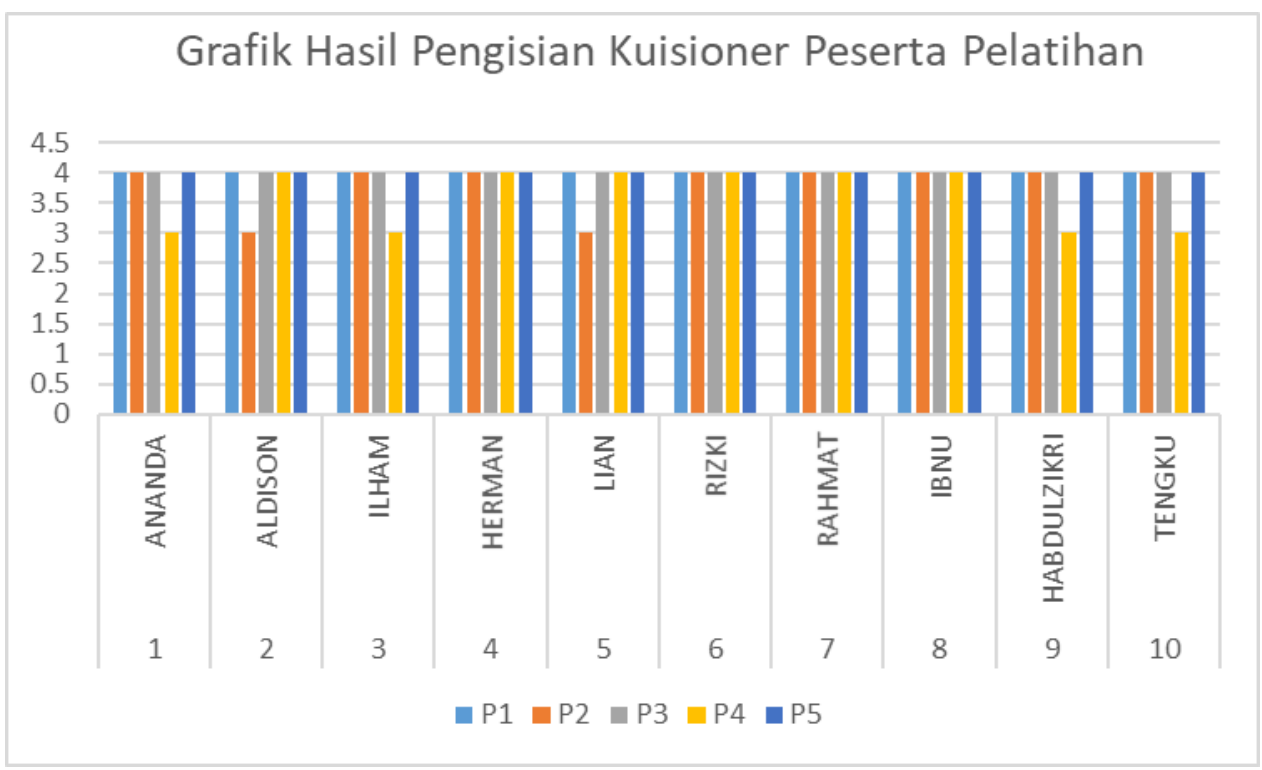

Gambar 3. Hasil Kuisioner Peserta Pelatihan

\section{Kesimpulan}

Berdasarkan hasil data dari penyebaran kuisioner, maka penulis dapat mengambil beberapa kesimpulan yaitu :

1 Pengetahuan peserta pelatihan tentang pembuatan logo menggunakan aplikasi pixellab berbasis mobile secara keseluruhan mengalami peningkatan.

2 Dengan adanya pelatihan ini dapat meningkatkan semangat mahasantri untuk mendalami pengetahuan desain grafis dalam hal ini cara membuat logo dengan apliakasi pixellab

3 Antusiasme para peserta pelatihan ini menunjukan peningkatan yang signifikan untuk menambah pengetahuan dalam membuat logo dengan mengunakan aplikasi pixellab berbasis mobile.

\section{Daftar Pustaka}

Dale, M. (2011). Collaborative video editing for Wikipedia. In Proceedings of the 7th International Symposium on Wikis and Open Collaboration - WikiSym '11 (p. 225). New York, New York, USA: ACM Press. https://doi.org/10.1145/2038558.2038607

Feinberg, M. A., Song, K.-B., \& Lim, I.-T. (2016). KineMaster - Pro video editing on android. ACM SIGGRAPH 2016 Appy Hour, SIGGRAPH 2016. https://doi.org/10.1145/2936744.2956677

Gandhi, V., Ronfard, R., \& Gleicher, M. (2014). Multi-clip video editing from a single viewpoint. In Proceedings of the 11th European Conference on Visual Media 
Production - CVMP '14 (pp. 1-10). New York, New York, USA: ACM Press. https://doi.org/10.1145/2668904.2668936

Guo, X., Cao, X., Chen, X., \& Ma, Y. (2013). Video editing with temporal, spatial and appearance consistency. Proceedings of the IEEE Computer Society Conference on Computer Vision and Pattern Recognition, 2283-2290. https://doi.org/10.1109/CVPR.2013.296

Martin, R. R., Shi-Min Hu, Jin Wei, Shao-Ping Lu, \& Song-Hai Zhang. (2012). Timeline Editing of Objects in Video. IEEE Transactions on Visualization and Computer Graphics, 19(7), 1218-1227. https://doi.org/10.1109/tvcg.2012.145

Marton, A., \& Mariátegui, J. C. (2015). De/Contextualizing Information: The Digitization of Video Editing Practices at the BBC. Information Society, 31(2), 106-120. https://doi.org/10.1080/01972243.2015.998102

Serrano, A., Sitzmann, V., Ruiz-Borau, J., Wetzstein, G., Gutierrez, D., \& Masia, B. (2017). Movie editing and cognitive event segmentation in virtual reality video. $A C M$ Transactions on Graphics, 36(4), 1-12. https://doi.org/10.1145/3072959.3073668

Shen, Y. (2016). A New Video Editing Technology in Practical Teaching for Animation Specialty. International Journal of Emerging Technologies in Learning (IJET), 11(09), 51. https://doi.org/10.3991/ijet.v11i09.6125

Tsai, J. C., Shih, T. K., Wattanachote, K., \& Li, K. C. (2012). Video editing using motion inpainting. Proceedings - International Conference on Advanced Information Networking and Applications, AINA, 649-654. https://doi.org/10.1109/AINA.2012.22 